\title{
"Two Truths" (satyadvaya) in the $d B u$ ma bden gnyis (Satyadvayavibhanga) of the Bon Religion
}

\author{
Kumagai Seiji
}

\section{Introduction}

The idea of "two truths" (satyadvaya, bden gnyis), which is emphasized in Buddhism, also exists in the Bon religion. In this article, as a part of the study of the idea of "two truths" of the Bon religion, I take up the $d B u$ ma bden gnyis kyi gzhung (BonBD) written by Yar me Shes rab 'od zer (1058-1132 $\left.{ }^{1)}\right)$. There is its commentary by a Bon authority, mNyam med Shes rab rgyal mtshan (1356-1415) and it is quoted in the Bon sgo gsal byed (BGSB) by Tre ston rGyal mtshan dpal (14c). Accordingly we can understand that the BonBD is an important treatise in the Bon religion concerning the idea of "two truths". I outline the idea of "two truths" in the Bon $B D$ as follows:

\section{2. "Two truths" (satyadvaya, bden gnyis)}

On the "two truths", the BonBD provides the following explanation:

"Two truths which eliminate the disease of adherence to the existence" 2)

"All manifest "principles" (dharma) exist as two truths" 3 )

\section{The subject of understanding the appearance}

There are four subjects of understanding the appearance, and they are as follows:

(1) "sufferer of eye disease" (mig skyon can) sees everything as double. ")

(2) "ordinary person" (so so'i skye bo) sees various things and becomes attached to them. ${ }^{5)}$

(3) "wisdom attained later" (rjes shes) understands that the appearance is like an illusion and false. 6)

(4) "meditative equilibrium of buddha" (sangs rgyas kyi mnyam bzhag) does not have any discursiveness nor has it any cognition. ${ }^{7)}$

4. "Convention"(samvrti, kun rdzob) 
According to the BonBD, "the definition of "conventional truth"(samvrtisatya) is the appearance of the objects which do not [truly] exist". ${ }^{8)}$ With regard to its etymology, the BonBD explains that "because it is an existence that by nature is covered by imagination, it is [the conventional] truth". 9)

On the classification of "convention", the BonBD explains "we admit that there are two "conventions", namely the pure [convention] and the impure [convention]. [The impure convention:] they consider all "principles" of the "wheel of life" (samsāra), namely various objects and subjects of cognition, as "truth" (satya) according to its appearance, and [its essence] is covered. [The pure convention: wisdom attained later] understands that the appearance is like a dream and an illusion, and objects are not covered [by imagination]. As far as the "impure convention", there are two types. Namely they are the "false [convention]" and the "true [convention]". [The "false convention":] a sufferer of an eye disease, who sees everything as double, has falsehood in both his sensory organ and the objects he perceives. [When he is] compared to someone who does not possess falsehood, [his objects are] designated as the "false [convention]". The "true convention" is what those who do not have defiled sensory organs, namely the people of the world grasp." 10 )

The classification of "convention" is as follows:

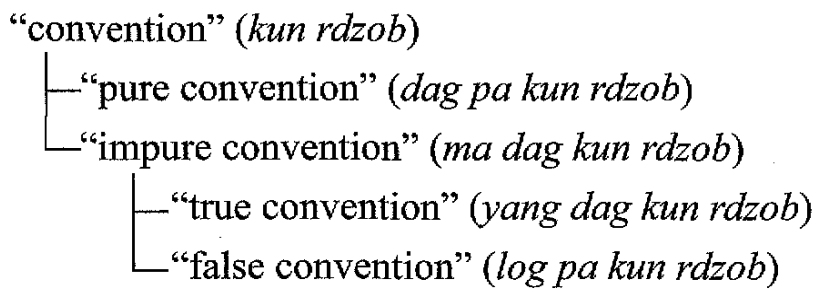

The correspondence between the conventions and the subjects of understanding appearance is as follows:

(1) "sufferer of eye disease": "false convention"

(2) "ordinary person": "real convention"

(3) "wisdom attained later": "pure convention"

(4) "meditative equilibrium of buddha": no correspondence

\section{5. "Absolute"(paramārtha, don dam)}

According to the BonBD, "the definition of the "absolute" is to be severed [and do not exist], but [as a linguistic expression it is explained as] being divorced from discursive 
ideas". 11)

With regard to its etymology, the BonBD explains that "[the "absolute" is] an object and an excellent one at that, or an object of excellent [wisdom]" ${ }^{12)}$. BonBD adopts the two interpretations, karmadhāraya and tatpurușa, but not the interpretation of bahuvrihi which is adopted as the third interpretation by Bhāviveka.

On the classification of the "absolute", BonBD explains that "the "absolute" is separated from discursive ideas and is not established as [an object]. [Its] number and classification are severed [and do not exist]. The teacher preached [the "absolute"] by [referring to its] numbers and similar examples and characterizing terms according to [the levels of] his disciples' thought". ${ }^{13)}$ The BonBD does not allow for the classification of the "absolute", [as it recognizes] only a single "absolute".

\section{Conclusion}

In this article, I outlined the structure of "two truths" of BonBD, as a part of study of "two truths" of the Bon religion. In other texts (e.g. BGSB), a different structure of "two truths" exists. It is my hope that the structures of "two truths" seen in those texts are clarified in future research.

Generally we accept that the Bon religion adopted a lot from the structure of ideas found in Buddhism and built its own structure of ideas. Then which idea of "two truths" in Buddhism did they adopt? In order to solve this problem, we need to compare the ideas of "two truths" of Buddhism and those of the Bon religion in detail.

\section{<Abbreviation $>$}

BGSB Bon sgo gsal byed of Tre ston rGyal mtshan dpal, ed. Mimaki and Samten (2007).

BonBD dBu ma bden gnyis kyi gzhung of Yar me (Me ston) Shes rab 'od zer, Sa lam rnam 'byed 'phrul sgron rtsa 'grel theg chen gzhi lam 'bras bu rtsa 'grel dbu ma rtsa 'grel skor gyi gsungs pod bzhungs, vol. 2 (Kha), Kathumandu, 1991, Text No. Cha (10 p.). (dBu ma bden gnyis kyi gzhung edited by Yam Lama and Samtin Jansin (read Sangye Tenzin and Samten Gyaltsen), Delhi, 1961)

BonBDG Theg pa chen po dBu ma bden gnyis kyi 'grel ba of mNyam med Shes rab rgyal mtshan, Sa lam rnam 'byed 'phrul sgron rtsa 'grel theg chen gzhi lam 'bras bu rtsa 'grel dbu ma rtsa 'grel skor gyi gsungs pod bzhungs, vol. 2 (Kha), Kathumandu, 1991, Text No. Ja (45 p.). 


\section{$<$ Bibliography $>$}

Mimaki and Karmay (2007): Katsumi Mimaki and Samten Karmay, Bon sgo gsal byed - Clarification of the Gates of Bon, A Fourteenth Century Bon po Doxographical Treatise-.

Kværne (1971): Per Kværne, "A Chronological Table of the Bon po : The Bstan reis of Nyi ma bstan "jin", Acta Orientalia, vol. 33, pp. 205-282.

Martin (2001): Dan Martin, Unearthing Bon Treasures - Life and Contested Legacy of a Tibetan Scripture Revealer, with a General Bibliography of Bon -, Leiden [Brill's Tibetan Studies Library, Vol. 1].

1) Martin (2001, pp. 75-76) suggests that the dates (1058-1132) presented by Kværne (1971, p. 230 ) should be pushed forward one cycle to (1118-1192). Since I have not done a thorough examination of all the documents, I will not take up this issue at this time.

2 ) dngos por 'dzin pa'i nad sel ba'i // bden pa rnam gnyis (BonBD1b1)

3 ) snang ba'i bon rnams kun // bden pa gnyis su rnam par gnas // (BonBD1b2)

4) mig skyon can la mig yor snang // (BonBDIb4)

5) byis pa so so'i skye bo la // sna tshogs snang zhing bden par zhen // (BonBD1b3)

6) dam pa'i rjes shes snang ba mams // sgyu ma bzhin du rdzun par rtogs // (BonBD1b3-4)

7) sangs rgyas dam pa'i mnyam bzhag la // spros med cir yang mthong mi 'gyur// (BonBD1b4)

8) kun rdzob bden pa'i mtshan nyid ni // yod pa ma yin don snang ba'o // (BonBD2a5-b1)

9) kun tu brtags pas sgrib par byed// mtshan ma'i dngos pos bden pa 'o// (BonBD2a1)

10) kun rdzob dbye ba gnyis su 'dod// dag pa dang ni ma dag pa'o// sna tshogs gzung 'dzin 'khor ba'i bon // snang bzhin bden mtshong 'grib par byed // snang ba rmi lam sgyu ma bzhin // der mthong don la 'grib mi 'gyur // ma dag kun rdzob rnam gnyis te // log pa dang ni yang dag go // mig skyon can la mig yor sogs // dbang po yul la skyon ldan pa // skyon med la ltos log par bzhag // yul dang dbang po ma bslad pas // "jig rten pa yis gang bzung ba // de ni yang dag kun rdzob yin // (BonBD2a2-4)

11) don dam mtshan nyid rnam par chad // 'on kyang spros pa rnams dang bral (BonBD2b1)

12) don yin dam pa yin pa 'am // dam pa rnams kyi yul yin la // (BonBD2a1)

13) don dam spros pa rnams dang bral // cir yang grub pa med pa la // grangs dang dbye ba rnam par chad // grangs dang mthun pa'i dpe dag dang // mtshon pa'i tshig gis gdul bya yi // bsam pa dang sbyar ston pas gsungs // (BonBD2a4-5)

〈key words〉 satyadvaya, paramārtha, samvrti, bden gnyis, don dam, kun rdzob, dag pa kun rdzob, ma dag kun rdzob, yang dag kun rdzob, log pa kun rdzob, Yar me shes rab 'od zer, mNyam med Shes rab rgyal mtshan

(Graduate Student, Kyoto University) 